\title{
PENGEMBANGAN ALAT UKUR MOTIVASI MEMBACA PADA REMAJA
}

\author{
Felicia $^{1}$, Sri Tiatri ${ }^{2}$, Heni Mularsih ${ }^{3}$ \\ Program Studi Magister Psikologi, Universitas Tarumanagara Jakarta \\ ${ }^{1}$ Email: felicia.shaa16@gmail.com \\ 2Email: sri.tiatri@untar.ac.id \\ ${ }^{3}$ Email: henim@mku.untar.ac.id
}

\begin{abstract}
ABSTRAK
Alat ukur motivasi membaca telah dikembangkan oleh berbagai studi alat ukur untuk mengukur motivasi membaca siswa/i TK dan SD (3-8 tahun). Penelitian ini bertujuan untuk mengadaptasi alat ukur Reading Motivation Questionnaire (RMQ) dari Schiefele dan Schaffner (2016) ke dalam bahasa Indonesia. RMQ mempunyai 34 butir dan 7 dimensi, antara lain rasa ingin tahu, keterlibatan, nilai akademik, kompetisi, pengakuan sosial, regulasi emosi dan bebas dari kebosanan. Alat ukur yang disusun diuji secara statistik untuk menghasilkan alat ukur yang valid dan reliabel. Proses penyusunan alat ukur yang dilakukan adalah menerjemahkan dari bahasa Inggris ke bahasa Indonesia, back translation dari bahasa Indonesia ke bahasa Inggris lalu mencocokkan dengan butir asli, validitas muka, penilaian ahli kepada tiga dosen ahli, dan revisi butir. Setelah direvisi, peneliti membuang butir-butir alat ukur yang tidak valid sehingga alat ukur motivasi membaca pada remaja memiliki 31 butir dengan 7 dimensi. Diadaptasi ke dalam bahasa Indonesia, peneliti mengubah butir-butir menjadi positif dan negatif. Setelah hasil adaptasi alat ukur sebanyak 37 butir diuji reliabilitas dan validitasnya, alat ukur motivasi membaca pada remaja reliabel (Cronbach's Alpha $=0,897$ ) dan valid secara konten dan konstruk. Dimensi yang memiliki butir-butir positif saja adalah dimensi regulasi emosi, sedangkan dimensi yang memiliki butir-butir negatif saja adalah dimensi pengakuan sosial. Pembahasan dan saran dibahas di dalam jurnal.
\end{abstract}

Kata kunci: alat ukur, motivasi membaca, remaja

\section{PENDAhuluan}

Motivasi membaca adalah konsep yang penting dibahas, khususnya dalam rangka meningkatkan kompetensi anak dalam menghadapi perkembangan dunia. Membaca itu penting karena menentukan kesuksesan anak di sekolah terutama anak-anak yang lebih besar yang sering menghadapi materi pelajaran dengan bacaan yang banyak (Guthrie, et al., 2007). Dengan membaca, mereka akan mendapatkan pengetahuan dan pengalaman baca tulis sebagai salah satu faktor pemrediksi kesuksesan negara (Central Connecticut State University [CCSU], 2016). Tindakan individu untuk membaca perlu didorong oleh motivasi terhadap suatu aktivitas (Ryan \& Deci, 2000). Motivasi terdiri dari 2 jenis, yaitu motivasi instrinsik dan motivasi ekstrinsik.

Penelitian tentang motivasi membaca membutuhkan alat ukur yang valid dan reliabel. Alat ukur untuk mengukur motivasi membaca anak-anak remaja usia 12-18 tahun di Indonesia masih sangat minim. Karena itu alat ukur motivasi membaca yang valid dan reliabel dibutuhkan. Tes yang dinyatakan valid akan menjadi dasar yang tepat, bermakna dan berguna bagi kesimpulan yang dibuat (Gregory, 2004). Reliabel artinya memberikan hasil yang konsisten jika diukur berulang kali (Gregory, 2004).

Motivasi membaca merupakan sebuah variabel yang multidimensi terutama jika diujikan kepada partisipan usia sekolah dasar ke atas (Guthrie, et al., 2007). Pengukuran motivasi membaca banyak diujikan kepada anak-anak usia prasekolah sampai usia sekolah dasar awal (kelas 1-3 SD) yang berasal dari luar Indonesia (Klauda, 2009; Morgan, Fuchs, Compton, Cordray, \& Fuchs, 2008). Motivasi membaca merupakan proses yang mendorong aktivitas membaca sehingga muncul kesiapan serta daya tahan untuk mencapai tujuan membaca (Schunk, Pintrich, \& Meece, 2012; Schiefele, et al., 
2012; Schaffner, Schiefele, \& Ulferts, 2013; Schiefele \& Schaffner, 2016). Berdasarkan definisi di atas, motivasi memiliki tiga komponen, antara lain aktivitas, tujuan serta inisiasi dan daya tahan dalam melakukan suatu aktivitas.

Alat ukur motivasi membaca awalnya disusun oleh Wigfield dan Guthrie (1997) dan diberi nama Motivation for Reading Questionnaire (MRQ). MRQ memiliki 11 dimensi, yaitu rasa ingin tahu, keterlibatan, nilai akademik, kompetisi, pengakuan, kepatuhan, tantangan, kepentingan, penghindaran tugas, alasan sosial, dan efikasi. Kemudian, MRQ ditelaah lebih lanjut melalui analisis faktor sehingga menyisakan 9 dimensi yang terdiri dari rasa ingin tahu atau minat, preferensi untuk tantangan, keterlibatan, efikasi diri, kompetisi, pengakuan, nilai akademik, interaksi sosial dan penghindaran tugas. Schiefele dan Schaffner (2016) membuat studi kualititatif mengenai MRQ dan membuat alat ukur motivasi membaca baru bernama Reading Motivation Questionnaire (RMQ). RMQ memiliki 7 dimensi, di antaranya 5 dimensi dari MRQ dan 2 dimensi hasil studi kualitatif mereka. Dimensidimensi ini terbagi menjadi tiga jenis motivasi, yaitu intrinsik (dimensi rasa ingin tahu dan keterlibatan), ekstrinsik (nilai akademik, kompetisi, pengakuan sosial), dan regulator (regulasi emosi dan bebas dari kebosanan). Motivasi membaca intrinsik adalah dorongan untuk membaca karena membaca itu sendiri memuaskan atau bermanfaat, sedangkan motivasi membaca ekstrinsik adalah dorongan untuk membaca karena alasan di luar kegiatan membaca dan isi bacaan (Schiefele \& Schaffner, 2016). Jenis motivasi regulator adalah dorongan membaca agar dapat mengatur kadar dan durasi respons emosional dalam mencapai suatu tujuan tertentu (Gross, Sheppes, \& Urry dikutip dalam Gross, 2013; Schiefele \& Schaffner, 2016).

Ketujuh dimensi tersebut terdiri dari rasa ingin tahu, keterlibatan, nilai akademik, kompetisi, pengakuan sosial, regulasi emosi dan bebas dari kebosanan (Schiefele \& Schaffner, 2016). Dimensidimensi tersebut dapat dijelaskan sebagai berikut. (1) Rasa ingin tahu, yaitu semangat membaca membuat orang mendapat manfaat membaca, yaitu dapat mempelajari lebih lanjut tentang topik bacaan yang diminati, (2) Keterlibatan, yaitu semangat membaca membuat orang mendapat manfaat membaca, yaitu dapat mengalami perasaan yang positif, seperti tenggelam dalam cerita atau mengalami tindakan imajinatif, (3) Nilai akademik, yaitu semangat membaca membuat orang mendapat manfaat membaca, yaitu dapat meningkatkan nilai akademik atau prestasi di sekolah, (4) Kompetisi, yaitu semangat membaca membuat orang mendapat manfaat membaca, yaitu dapat mengungguli teman sekelas di sekolah, (5) Pengakuan sosial, yaitu semangat membaca membuat orang mendapat manfaat membaca, yaitu mendapatkan pujian karena sering membaca, (6) Regulasi emosi, yaitu semangat membaca membuat orang mendapat manfaat membaca, yaitu mampu mengatasi emosi negatif seperti amarah atau kesedihan, dan (7) Bebas dari kebosanan, yaitu Semangat membaca membuat orang mendapat manfaat membaca sehingga dapat mengatasi kebosanan dan mengisi waktu karena aktivitas yang lebih diinginkan tidak tersedia.

\section{Rumusan Masalah}

Berdasarkan gambaran kondisi di atas, peneliti bermaksud menjawab pertanyaan penelitian terkait alat ukur motivasi membaca pada remaja. Pertanyaan penelitian yang dimaksud adalah apakah alat ukur motivasi membaca pada remaja yang dikembangkan sudah valid dan reliabel? 


\section{METODE PENELITIAN Partisipan}

Teknik pengambilan sampel yang dilakukan adalah teknik pengambilan sampel secara acak kelas. Populasi siswa di SMA X berjumlah 265 orang. Setelah diundi, terpilih 4 kelas yang mewakili populasi siswa SMA X, yaitu 2 kelas 2 SMA (34 orang) dan 2 kelas 3 SMA (40 orang). Partisipan penelitian ini adalah 74 siswa/i dari SMA X, yaitu sebuah sekolah menengah atas swasta di Tangerang Selatan. Usia mereka berkisar antara 15 tahun hingga 19 tahun dengan rata-rata usia 16,68 tahun. Jumlah partisipan laki-laki 36 orang (49\%) dan perempuan 38 orang (51\%).

\section{Prosedur}

Mengacu pada saran dari Sugiyono (2012), maka alat ukur penelitian disusun berdasarkan 3 tahap, yaitu (1) membuat definisi operasional dari variabel penelitian (2) menentukan indikator yang akan diukur, (3) menjabarkan butir-butir pertanyaan atau pernyataan. Semua tahap tersebut dirangkum dalam sebuah kisi-kisi alat ukur atau blueprint. Peneliti mengadaptasi alat ukur motivasi membaca Reading Motivation Questionnaire $(R M Q)$ untuk mengukur motivasi membaca remaja di Indonesia.

Secara operasional, motivasi membaca dapat diartikan sebagai antusiasme yang tercermin dalam dorongan/ semangat sehingga muncul kesiapan untuk melakukan aktivitas membaca yang dapat diukur melalui dimensi rasa ingin tahu, keterlibatan, nilai akademik, kompetisi, pengakuan sosial, regulasi emosi dan bebas dari kebosanan (Schunk, Pintrich, \& Meece, 2012; Schiefele, et al., 2012; Schaffner, Schiefele, \& Ulferts, 2013; Schiefele \& Schaffner, 2016). Berdasarkan definisi operasional di atas, motivasi membaca dibagi menjadi 7 dimensi, antara lain (a) rasa ingin tahu, (b) keterlibatan, (c) nilai akademik, (d) kompetisi, (e) pengakuan sosial, (f) regulasi emosi, dan (g) bebas dari kebosanan (Schiefele \& Schaffner, 2016).

Langkah-langkah penyusunan alat ukur yang peneliti lakukan adalah (1) penerjemahan alat ukur, (2) back translation, (3) validitas muka dengan siswa SMA, (4) penilaian ahli, (5) revisi butir. Pertama, peneliti menerjemahkan RMQ ke dalam bahasa Indonesia dari bahasa Inggris. Kedua peneliti meminta seorang Warga Negara Indonesia (WNI) yang fasih berbahasa Inggris (lulusan doktoral dari universitas di Amerika) untuk menerjemahkan kembali kuesioner tersebut ke dalam bahasa Inggris. Hasil terjemahan bahasa Inggris tersebut dicocokkan dengan butir kuesioner asli, mengalami revisi satu kali, lalu diterjemahkan kembali ke dalam bahasa Inggris. Setelah itu, hasilnya dicocokkan kembali dengan butir kuesioner asli. Tingkat kecocokkannya tinggi (97,2\% dari butir hasil back translation memiliki makna yang sama dengan butir asli kuesioner dalam bahasa Inggris).

Ketiga, peneliti menguji validitas muka kuesioner dalam bahasa Indonesia yang telah lolos dalam tahap back to back translation. Uji validitas muka kuesioner ini dilakukan kepada 3 orang siswa SMA $X$. Peneliti mendapat masukan mengenai pemilihan kata yang sesuai dengan pengetahuan mereka sebagai perwakilan remaja. Selain itu, mereka memberi ide bagi peneliti untuk menyusun kuesioner menjadi lebih mudah dibaca dan dimengerti.

Keempat, peneliti meminta penilaian ahli (expert judgment), yaitu dari tiga orang dosen Psikologi Pendidikan Universitas Tarumanagara Jakarta yang sering berkecimpung dalam bidang membaca. 
Hasil dari penilaian ahli menunjukkan ada 28 butir dari 37 butir yang dianggap sudah mengukur hal yang diukur oleh tiga ahli.

Kelima, berdasarkan penilaian ahli tersebut, peneliti mendapatkan masukan untuk melakukan revisi butir serta menambahkan butir-butir negatif dalam alat ukur motivasi membaca pada remaja. Selain itu, dosen-dosen memberikan masukan bahwa butir-butir alat ukur perlu disusun secara lebih bervariasi baik dalam konten maupun pemilihan kata-kata. Namun, peneliti diingatkan untuk tetap konsisten dalam menyusun butir-butir agar mengukur dimensi yang dituju. Tabel 1 menunjukkan hasil adaptasi alat ukur motivasi membaca pada remaja, sementara Tabel 2 menunjukkan Contoh Butir Kuesioner Motivasi Membaca pada Remaja.

Tabel 1. Kisi-Kisi Kuesioner Motivasi Membaca pada Remaja

\begin{tabular}{cccc}
\hline \multirow{2}{*}{ Dimensi } & \multicolumn{2}{c}{ Butir Alat Ukur } & Total \\
\cline { 2 - 4 } Rasa Ingin Tahu & $1,8,15,20$ & 23,30 & 6 \\
Keterlibatan & $2,9,16,21$ & 24,31 & 6 \\
Ekstrinsik & & & \\
Nilai Akademik & 3,10 & 25,32 & 4 \\
Kompetisi & 4,11 & 26,33 & 4 \\
Pengakuan Sosial & $5,12,17$ & $27,34,37$ & 6 \\
Regulator & & & \\
Regulasi Emosi & $6,13,18$, & 28,35 & 6 \\
Bebas dari & 22 & & \\
Kebosanan & $7,14,19$ & 29,36 & 5 \\
Total Butir & 22 & 15 & 37 \\
\hline
\end{tabular}


Tabel 2. Contoh Butir Kuesioner Motivasi Membaca pada Remaja

\begin{tabular}{|c|c|}
\hline Dimensi & Butir Positif \\
\hline \multicolumn{2}{|l|}{ Intrinsik } \\
\hline Rasa Ingin Tahu & $\begin{array}{l}1(+) \text { Saya bersemangat membaca agar saya memperoleh } \\
\text { pemahaman tentang topik tertentu. } \\
23 \text { (-) Saya tidak bersemangat membaca meskipun topik bacaan } \\
\text { tersebut menarik. }\end{array}$ \\
\hline Keterlibatan & $\begin{array}{l}2(+) \text { Saya bersemangat membaca agar saya dapat berimajinasi } \\
\text { tentang bacaan tersebut. } \\
24(-) \text { Saya tidak bersemangat membaca padahal saya tahu akan } \\
\text { mendapatkan gambaran cerita lebih utuh dengan membaca. }\end{array}$ \\
\hline \multicolumn{2}{|l|}{ Ekstrinsik } \\
\hline Nilai Akademik & $\begin{array}{l}3(+) \text { Saya bersemangat membaca karena ingin memperoleh nilai } \\
\text { pelajaran yang lebih baik di sekolah. } \\
25(-) \text { Saya tidak bersemangat membaca meskipun membaca } \\
\text { dapat meningkatkan prestasi saya. }\end{array}$ \\
\hline Kompetisi & $\begin{array}{l}4(+) \text { Saya bersemangat membaca agar saya lebih mudah } \\
\text { mengerti isi bacaan dibandingkan dengan teman-teman sekolah } \\
\text { saya. } \\
26(-) \text { Saya tidak bersemangat membaca padahal saya tahu } \\
\text { pengetahuan saya akan bertambah karena membaca dibandingkan } \\
\text { dengan teman-teman sekolah saya. }\end{array}$ \\
\hline Pengakuan Sosial & $\begin{array}{l}12(+) \text { Saya bersemangat membaca agar orang lain berpikir } \\
\text { bahwa saya rajin membaca. } \\
34 \text { (-) Saya tidak bersemangat membaca walaupun teman-teman } \\
\text { saya sering membaca. }\end{array}$ \\
\hline Regulator & \\
\hline Regulasi Emosi & $\begin{array}{l}6(+) \text { Saya bersemangat membaca agar saya dapat mengatasi } \\
\text { kegelisahan saya. } \\
28 \text { (-) Saya tidak bersemangat membaca padahal membaca dapat } \\
\text { membantu saya mengatasi kesedihan saya. }\end{array}$ \\
\hline Bebas dari Kebosanan & $\begin{array}{l}7 \text { (+) Saya bersemangat membaca agar dapat mengisi waktu } \\
\text { kosong. } \\
29 \text { (-) Saya tidak bersemangat membaca karena saya tetap bosan } \\
\text { dengan membaca. }\end{array}$ \\
\hline
\end{tabular}


Setelah menyusun butir-butir alat ukur, peneliti menuliskan petunjuk pengisian dan membuat kolom identitas. Pilihan jawaban yang tersedia adalah $1=$ Sangat Tidak Setuju, $2=$ Tidak Setuju, $3=$ Setuju, 4 = Sangat Setuju. Peneliti menjelaskan bahwa keikutsertaan partisipan dalam penelitian ini bersifat sukarela dan partisipan dapat mengundurkan diri dengan mengembalikan lembar kuesioner kosong tanpa jawaban. Pernyataan positif dinilai sesuai pilihan jawaban di atas. Namun, pernyataan negatif dinilai secara terbalik, yaitu 1 = Sangat Setuju, 2 = Setuju, 3 = Tidak Setuju, 4 = Sangat Tidak Setuju .

\section{HASIL DAN PEMBAHASAN Analisis Data}

Pengujian reliabilitas internal dilakukan dengan melihat nilai Cronbach Alpha menggunakan program SPSS 20 for MacOS. Pengujian validitas yang dilakukan adalah validitas muka, validitas konten (penilaian ahli), dan validitas konstruk (Corrected Item-Total Correlation). Validitas muka dilakukan dengan memberikan kuesioner kepada tiga orang remaja dari Sekolah X. Validitas konten ditinjau dari nilai content validity ratio (CVR) dan content validity index (CVI). Validitas konstruk akan menjadi acuan dalam pengurangan butir alat ukur.

\section{Hasil Analisis}

Setelah meminta para ahli untuk menilai butir-butir alat ukur motivasi membaca pada remaja, peneliti merevisi butir-butir alat ukur sampai semua ahli sepakat menyetujui butir-butir alat ukur yang digunakan. Oleh karena itu, nilai CVR yang dicapai adalah 1. Berdasarkan hasil validitas muka terhadap siswa/i SMA, butir-butir yang kurang tepat secara redaksional maupun teknis pelaksanaan pengambilan data yang kurang tepat dicatat dan direvisi oleh peneliti.

Hasil analisis dengan 74 sampel menunjukkan bahwa tingkat reliabilitas dari alat ukur motivasi membaca pada remaja tergolong baik (Cronbach's Alpha $=0,881$ ). Standar reliabilitas yang digunakan adalah 0,7 (Gliem \& Gliem, 2003). Berdasarkan tabel Pearson $r$ dalam Gravetter dan Wallnau (2008), r tabel untuk jumlah sampel 74 orang adalah 0,235. Sementara itu, hasil uji validitas konstruk yang dilihat dari korelasi butir-total menunjukkan terdapat 32 butir yang valid $\left(\mathrm{r}<\mathrm{r}_{\text {tabel }}=\right.$ $0,235, \mathrm{p}<0,05)$. Butir yang dibuang berdasarkan uji validitas konstruk ini adalah nomor 3, 5, 12, 28, dan 35. Tabel 3 menunjukkan hasil uji reliabilitas. 


\begin{tabular}{|c|c|c|c|c|c|c|}
\hline $\begin{array}{l}\text { No. } \\
\text { Butir }\end{array}$ & $\begin{array}{c}\text { Korelasi } \\
\text { Butir- } \\
\text { Total } \\
\text { Dikoreksi }\end{array}$ & $\begin{array}{l}\text { No. } \\
\text { Butir }\end{array}$ & $\begin{array}{c}\text { Korelasi } \\
\text { Butir-Total } \\
\text { Dikoreksi }\end{array}$ & $\begin{array}{l}\text { No. } \\
\text { Butir }\end{array}$ & $\begin{array}{l}\text { Korelasi Butir- } \\
\text { Total Dikoreksi }\end{array}$ & $\begin{array}{c}\text { Tabel 3. Hasil Uji } \\
\text { Reliabilitas ( } 37 \\
\text { Butir) }\end{array}$ \\
\hline 1 & $0,238^{*}$ & 14 & $0,364 *$ & 27 & $0,398^{*}$ & \\
\hline 2 & $0,438^{*}$ & 15 & $0,337 *$ & 28 & $-0,306$ & \\
\hline 3 & 0,230 & 16 & $0,359 *$ & 29 & $0,608 *$ & \\
\hline 4 & $0,494 *$ & 17 & $0,355^{*}$ & 30 & $0,470 *$ & \\
\hline 5 & 0,102 & 18 & $0,590 *$ & 31 & $0,642 *$ & \\
\hline 6 & $0,380^{*}$ & 19 & $0,360^{*}$ & 32 & $0,397 *$ & \\
\hline 7 & $0,446^{*}$ & 20 & $0,348^{*}$ & 33 & $0,397 *$ & \\
\hline 8 & $0,340 *$ & 21 & $0,443 *$ & 34 & $0,568 *$ & \\
\hline 9 & $0,426^{*}$ & 22 & $0,685^{*}$ & 35 & 0,206 & \\
\hline 10 & $0,369 *$ & 23 & $0,278^{*}$ & 36 & $0,630 *$ & \\
\hline 11 & $0,294 *$ & 24 & $0,352 *$ & 37 & $0,510 *$ & \\
\hline 12 & 0,171 & 25 & $0,485^{*}$ & & & \\
\hline 13 & $0,477 *$ & 26 & $0,377^{*}$ & & & \\
\hline
\end{tabular}

Setelah itu, peneliti melakukan uji reliabilitas dan validitas konstruk butir-total untuk yang kedua kalinya. Hasilnya menunjukkan reliabilitas alat ukur yang tinggi dengan Cronbach's Alpha senilai 0,895. Butir dengan korelasi butir-total yang berada di bawah $r$ tabel dibuang oleh peneliti, yaitu nomor $17\left(\mathrm{r}<\mathrm{r}_{\text {tabel }}=0,235, \mathrm{p}<0,05\right)$. Setelah membuat butir yang tidak valid, peneliti melakukan uji reliabilitas dan validitas kembali. Hasilnya menyatakan bahwa 31 butir yang ada valid dan reliabel (Cronbach's Alpha=0,897). Tabel 4 menunjukkan hasil uji reliabilitas dengan 32 butir. Tabel 5 menunjukkan kisi-kisi alat ukur motivasi membaca pada remaja yang sudah valid secara konten dan konstruk. 
Tabel 4. Hasil Uji Reliabilitas (32 Butir)

\begin{tabular}{|c|c|c|c|c|c|}
\hline $\begin{array}{l}\text { No. } \\
\text { Butir }\end{array}$ & $\begin{array}{c}\text { Korelasi } \\
\text { Butir- } \\
\text { Total } \\
\text { Dikoreksi }\end{array}$ & $\begin{array}{l}\text { No. } \\
\text { Butir }\end{array}$ & $\begin{array}{c}\text { Korelasi } \\
\text { Butir- } \\
\text { Total } \\
\text { Dikoreksi }\end{array}$ & $\begin{array}{l}\text { No. } \\
\text { Butir }\end{array}$ & $\begin{array}{c}\text { Korelasi } \\
\text { Butir- } \\
\text { Total } \\
\text { Dikoreksi }\end{array}$ \\
\hline 1 & $0,242 *$ & 15 & $0,314 *$ & 26 & $0,363^{*}$ \\
\hline 2 & $0,446^{*}$ & 16 & $0,386^{*}$ & 27 & $0,423^{*}$ \\
\hline 4 & $0,451^{*}$ & 17 & 0,204 & 29 & $0,629 *$ \\
\hline 6 & $0,377^{*}$ & 18 & $0,624^{*}$ & 30 & $0,480^{*}$ \\
\hline 7 & $0,481 *$ & 19 & $0,355^{*}$ & 31 & $0,652 *$ \\
\hline 8 & $0,351 *$ & 20 & $0,315^{*}$ & 32 & $0,395^{*}$ \\
\hline 9 & $0,437 *$ & 21 & $0,461 *$ & 33 & $0,396^{*}$ \\
\hline 10 & $0,337 *$ & 22 & $0,692 *$ & 34 & $0,579 *$ \\
\hline 11 & $0,247 *$ & 23 & $0,318 *$ & 36 & $0,649 *$ \\
\hline 13 & $0,480 *$ & 24 & $0,373 *$ & 37 & $0,537^{*}$ \\
\hline 14 & $0,383 *$ & 25 & $0,478 *$ & & \\
\hline
\end{tabular}


Tabel 5. Kisi-Kisi Kuesioner Motivasi Membaca pada Remaja yang Sudah Valid

\begin{tabular}{lccc}
\hline \multirow{2}{*}{ Dimensi } & \multicolumn{2}{c}{ Butir Alat Ukur } & \\
\cline { 2 - 3 } Intrinsik & Positif & Negatif & Total \\
Rasa Ingin Tahu & $1,8,15,20$ & 23,30 & 6 \\
Keterlibatan & $2,9,16,21$ & 24,31 & 6 \\
$\begin{array}{l}\text { Ekstrinsik } \\
\text { Nilai Akademik }\end{array}$ & 10 & 25,32 & 3 \\
Kompetisi & 4,11 & 26,33 & 4 \\
Pengakuan Sosial & - & $27,34,37$ & 3 \\
$\begin{array}{l}\text { Regulator } \\
\text { Regulasi Emosi }\end{array}$ & $6,13,18$, & & \\
$\quad 22$ & - & 4 \\
Bebas dari Kebosanan & $7,14,19$ & 29,36 & 5 \\
$\quad$ Total Butir & 18 & 13 & 31 \\
\hline
\end{tabular}

Ketiga jenis motivasi membaca, yaitu intrinsik, ekstrinsik dan regulator, diuji secara korelatif. Motivasi membaca intrinsik dan ekstrinsik berkorelasi positif, $r=0,565, n=74, p=0,000$. Motivasi membaca intrinsik dan regulator menunjukkan hubungan yang positif, $\mathrm{r}=0,698, \mathrm{n}=74, \mathrm{p}=0,000$. Motivasi membaca ekstrinsik dan regulator pun memiliki korelasi yang positif, $\mathrm{r}=0,430, \mathrm{n}=74, \mathrm{p}=$ 0,000 . Korelasi atau hubungan yang positif artinya semakin tinggi satu jenis motivasi, semakin tinggi pula jenis motivasi yang lainnya.

\section{Pembahasan}

Hasil uji reliabilitas dan validitas alat ukur motivasi membaca pada remaja menyatakan bahwa alat ukur tersebut sudah reliabel dan valid serta layak untuk dipakai dalam penelitian-penelitian. Jumlah butir alat ukur yang terakhir adalah 31 butir dengan 7 dimensi. Dimensi-dimensi tersebut terdiri dari rasa ingin tahu, keterlibatan, nilai akademik, kompetisi, pengakuan sosial, regulasi emosi dan bebas 
dari kebosanan. Alat ukur ini dapat digunakan untuk mengukur motivasi membaca pada remaja, khususnya pada jenjang SMA.

Butir-butir positif pada dimensi pengakuan sosial menjadi tidak ada sedangkan butir-butir negatif dimensi-dimensi tersebut masih utuh seperti sebelum pengujian reliabilitas dan validitas. Partisipan terlihat lebih menunjukkan motivasi membaca yang didasari oleh pengakuan sosial jika dihadapkan dengan butir negatif daripada diberikan butir positif. Pengakuan sosial, artinya mendapatkan pujian karena membaca. Partisipan menunjukkan motivasi yang didasari oleh pengakuan sosial secara implisit dari butir-butir negatif.

Sementara itu, butir-butir negatif pada dimensi regulasi emosi menjadi tidak ada. Partisipan terlihat lebih jelas menunjukkan motivasi membacanya dalam dimensi regulasi emosi melalui butir-butir positif. Butir-butir tersebut menunjukkan kesan yang negatif bagi siswa karena emosi negatif disertai dengan motivasi membaca yang rendah. Menurut Gross, Richards, dan John (dikutip dalam Gross, 2013), orang cenderung mengurangi emosi negatif yang dialami. Oleh karena itu, emosi negatif yang ada dalam butir negatif motivasi membaca membuat orang mengalami emosi negatif tersebut.

\section{KESIMPULAN DAN SARAN}

Alat ukur motivasi membaca pada remaja dinyatakan valid dan reliabel setelah melalui prosedur penyusunan alat tes dengan baik. Terdapat 31 butir yang terbagi menjadi 7 dimensi, yaitu rasa ingin tahu, keterlibatan, nilai akademik, kompetisi, pengakuan sosial, regulasi emosi dan bebas dari kebosanan. Populasi yang sesuai untuk menggunakan alat ukur ini adalah remaja pada jenjang SMA. Namun, jumlah sampel sebanyak 74 siswa belum memadai menjadikan alat ukur ini belum dapat digeneralisasikan kepada populasi remaja SMA. Bagi pengembangan alat ukur motivasi membaca pada remaja berikutnya, peneliti menyarankan untuk menambah jumlah partisipan agar lebih mewakili populasi remaja SMA. Semakin banyak partisipan, semakin dapat dipercaya sebuah penelitian. Pada dimensi pengakuan sosial, partisipan remaja lebih terbuka dalam menjawab butirbutir negatif daripada butir-butir positif sehingga perlu memperbanyak butir-butir negatif untuk diujikan. Penelitian selanjutnya perlu mengkaji pula apakah faktor sosial ekonomi dan faktor budaya berperan dalam motivasi membaca remaja.

\section{Ucapan Terima Kasih (Acknowledgement)}

Atas keberhasilan penelitian ini, kami mengucapkan terima kasih kepada Universitas Tarumanagara yang telah memberikan izin untuk penggunaan sarana dan prasarana kampus yang tersedia, kepada

Sekolah X dan seluruh staf pengajarnya yang telah mengizinkan kami untuk mengambil data siswa/i di tempatnya, dan kepada pihak-pihak yang membantu dan mendukung penelitian ini.

\section{REFERENSI}

Central Connecticut State University. (2016). World's Most Literate Nations Ranked. Diunduh dari http://webcapp.ccsu.edu/?news=1767\&data

Gliem, J. A. \& Gliem, R. R. (2003). Calculating, Interpreting, and Reporting Cronbach's Alpha Reliability Coefficient for Likert-Type Scales, Midwest Research-to-Practice Conference, Ohio, October 8-10. Columbus, OH: Adult, Continuing, and Community Education.

Gravetter, F. J. \& Wallnau L. B. (2008). Essentials of Statistics for the Behavioral Sciences, $6^{\text {th }}$ Ed. Belmont, CA: Thomson Wadsworth. 
Gregory, R. J. (2004). Psychological Testing: History, Principles, and Applications, $4^{\text {th }}$ Ed. Boston, MA: Allyn and Bacon.

Gross, J. J. (2013). Emotion regulation: taking stock and moving forward. Emotion, 13 (3), 359-365.

Guthrie, J. T., Hoa, A. L. W., Wigfield, A., Tonks, S. M., Humenick, N. M., \& Littles, E. (2007). Reading motivation and reading comprehension growth in the later elementary years. Contemporary $\quad$ Educational 282-313. https://doi.org/10.1016/j.cedpsych.2006.05.004

Klauda, S. L. (2009). The role of parents in adolescents' reading motivation and activity. Educational Psychology Review, 21(4), 325-363. https://doi.org/10.1007/s10648-009-9112-0

McGeown, S., Goodwin, H., Henderson, N., \& Wright, P. (2012). Gender differences in reading motivation: Does sex or gender identity provide a better account? Journal of Research in Reading, 35(3), 328-336. https://doi.org/10.1111/j.1467-9817.2010.01481.x

Morgan, P. L., Fuchs, D., Compton, D. L., Cordray, D. S., \& Fuchs, L. S. (2008). Does early reading failure decrease children's motivation? Journal of Learning Disabilities, 41(5), 387-404.

Ryan, R. M. \& Deci, E. L. (2000). Intrinsic and extrinsic motivations: Classic definitions and new directions. Contemporary Educational Psychology, 25, 54-67. https://doi.org/10.1006/ceps.1999.1020

Schaffner, E., Schiefele, U., \& Ulferts, H. (2013). Reading amount as a mediator of the effects of intrinsic and extrinsic reading motivation on reading comprehension. Reading Research Quarterly, 48(4), 369-385. https://doi.org/10.1002/rrq.52

Schiefele, U., \& Schaffner, E. (2016). Factorial and construct validity of a new instrument for the assessment of reading motivation. Reading Research Quarterly, 51(2), 221-237. https://doi.org/10.1002/rrq.134

Schiefele, U., Schaffner, E., Möller, J., Wigfield, A., Nolen, S., \& Baker, L. (2012). Dimensions of reading motivation and their relation to reading behavior and competence. Reading Research Quarterly, 47(4), 427-463. https://doi.org/10.1002/RRQ.030

Schunk, D. H., Pintrich, P. R., \& Meece, J. L. (2012). Motivasi dalam Pendidikan: Teori, Penelitian dan Aplikasi, Edisi Ketiga. Jakarta, Indonesia: PT Indeks.

Stutz, F., Schaffner, E., \& Schiefele, U. (2016). Measurement invariance and validity of a brief questionnaire on reading motivation in elementary students. Journal of Research in Reading, 0(0), 1-23. https://doi.org/10.1111/1467-9817.12085

Sugiyono. (2012). Metode Penelitian Kuantitatif, Kualitatif, dan R\&D. Bandung: Alfabeta.

Wigfield, A., \& Guthrie, J. T. (1997). Relations of children's motivation for reading to the amount and breadth or their reading. Journal of Educational Psychology, 89(3), 420-432. https://doi.org/10.1037/0022-0663.89.3.420 